\title{
San Francisco de Paula. Origen y relaciones de un rancho fundado por afrodescendientes en el Yucatán independiente
}

\section{San Francisco de Paula. Origin and Relationships of a Ranch Founded by Afro-descendants in Independent Yucatán}

\author{
Jorge Victoria Ojeda \\ (D) https://orcid.org/0000-0003-4468-0901 \\ Universidad Autónoma de Yucatán, México \\ jorge.victoria@correo.uady.mx
}

Resumen: El objetivo del texto es esclarecer en lo posible el origen de los primeros pobladores del rancho San Francisco de Paula y demostrar el contacto que tuvo con San Fernando Aké, ambos sitios fundados por afrodescendientes. Se propone que sus primeros moradores llegaron de Cuba en 1823. La investigación está basada principalmente en fuentes primarias. Los resultados sacan a la luz las desconocidas interrelaciones entre los afrodescendientes que vivían en las periferias circuncaribeñas y la región yucateca. La información sobre el asentamiento constituye una aportación a la historia regional por la temporalidad del suceso, por la coyuntura política de su arribo y por los contactos posteriores. La historia del poblado siguió, aparentemente sin mayor notoriedad, el mismo sendero que las restantes comunidades yucate-

Cómo citar: Victoria Ojeda, J. (2021). San Francisco de Paula. Origen y relaciones de un rancho fundado por afrodescendientes en el Yucatán independiente. Secuencia (109), e1752. DoI: https://doi.org/10.18234/ secuencia.v0i109.1752 
cas, mientras las autoridades y la prensa locales se encargaban de silenciar el pasado y el presente de los africanos y afrodescendientes.

Palabras clave: San Francisco de Paula; San Fernando Aké; afrodescendientes; Cuba; interrelaciones.

Abstract: The purpose of the text is to shed as much light as possible on the origin of the first settlers of the San Francisco de Paula ranch and show the contact they had with San Fernando Aké, both of which were founded by Afro-descendants. It is suggested that its first inhabitants arrived from Cuba in 1823. The research is based mainly on primary sources. The results bring to light previously unknown interrelationships between Afro-descendants who lived in the circum-Caribbean peripheries and the Yucatecan region. The information on the settlement constitutes a contribution to regional history due to the time of the event, the political circumstances of the inhabitants' arrival and subsequent contacts. The history of the town apparently followed much the same unexceptional path as other Yucatecan communities, while the local authorities and press took it upon themselves to silence the past and present of Africans and Afro descendants.

Key words: San Francisco de Paula; San Fernando Aké; Afro-descendants; Cuba; interrelationships.

Recibido: 27 de mayo de 2019 Aceptado: 27 de abril de 2020

Publicado: 2 de marzo de 2021

\section{INTRODUCCIÓN}

Чace unos años se publicó un texto donde se abordaban datos históricos 1 de dos poblados de africanos y afrodescendientes en Yucatán: San Fernando Aké y San Francisco de Paula (Victoria, 2011). Acerca del primer sitio la información es bastante amplia ya que existe documentación referente a la procedencia de los fundadores, hecho suscitado en 1796, hasta su abandono en 1848. Del segundo, en aquella publicación se hacían algunas inferencias, y 
se indicaba que "no se cuenta con información documental para interpretar su historia; únicamente se tiene una nota referente al poblado, proveniente de 1837" (Victoria, 2011, pp. 292-230). ${ }^{1}$ Otras publicaciones que se han ocupado del sitio son la de Robles y Andrews (2004), resultados preliminares de un trabajo arqueológico, y la de Restall (2009). ${ }^{2}$

Según Robles y Andrews (2004), el origen del rancho proviene de "fines de la Colonia, como refugio de los negros que habían huido de la esclavitud". La temporalidad, al parecer, se complementa con base en la evidencia cerámica que apunta a que el asentamiento pudo originarse a finales del siglo XVIII o inicios del XIX (Restall, 2009, p. 225). ${ }^{3}$ Este autor opina que los afrodescendientes fundadores del rancho San Francisco de Paula (entre los que se incluirían pardos ${ }^{4}$ y mulatos libres ${ }^{5}$ ) pudieron provenir de la ciudad de Mérida y de la población de Hunucmá, próxima al puerto de Sisal, con intenciones de aprovechar los recursos naturales de la zona: leña, agua, la cercanía a la costa y la ubicación del rancho no lejos del traficado camino entre las poblaciones apuntadas. ${ }^{6}$ El movimiento de esa gente parece explicable en el contexto de su crecimiento poblacional y migración (Restall, 2009, pp. 150, 182-183, 225-226).

Victoria (2011, pp. 311-312, 322), tras un ejercicio de eliminación por ausencia de su mención en ciertos documentos históricos, propuso que aquel asentamiento de "morenos", tal como se designa a sus moradores en el texto del gobierno estatal en 1837, provenía de inicios de la década de 1830. Apuntó

${ }^{1}$ Restall (2009, p. 150) también señala la ausencia de información sobre el sitio en los archivos. Para más datos acerca de San Fernando Aké, véase Victoria y Canto (2006).

${ }^{2}$ Este autor retoma parte de los resultados preliminares de los arqueólogos y los enriquece con sus aportaciones y comentarios.

${ }^{3}$ Restall (2009) cree que San Francisco de Paula fue fundado "around the same time as San Fernando Ake and inhabited through the nineteenth century by Afro-Yucatecans" (p. 182). Este autor aporta ideas en cuanto al asentamiento con base en su amplia experiencia sobre el tema de los africanos en Yucatán.

${ }^{4}$ En origen, los pardos eran el resultado de la unión de un africano y una maya, sin embargo, la denominación se continuó aplicando para los hijos de los pardos. Al ser descendientes de mujer maya los hijos nacían libres, aunque su padre fuese esclavo. Culturalmente, este grupo estaba dentro del ámbito de lo maya, aunque en lo biológico tenían parte de africano. Para el tema, véase Restall (2009), quien los denomina afro-mayas.

${ }^{5}$ Los mulatos eran los hijos de españoles y negras, sin embargo, el término se utilizó como genérico de la población en parte negra, así como se usó también el de pardo (Fernández y Negroe, 1995, p. 19).

${ }^{6}$ La actividad a la que se dedicaban los moradores del rancho fue el corte y tráfico de palo de tinte y el comercio legal e ilegal de mercancías (Restall, 2009, pp. 224-226; Victoria, 2011, p. 320). 
que para inicios de la tercera década del siglo xix un grupo de afrodescendientes ocupó un sitio cercano a Sisal, pero pensaba que no fue gente en estado de esclavitud que escapó de una finca de la zona de Cayal, en Campeche, como apunta la tradición oral recopilada en Sisal y Hunucmá, sino que era gente libre que provenía de aquella región campechana una vez declarada la liberación de los esclavos en 1829.

La temporalidad propuesta del sitio va de 1830 hasta 1916, más o menos, cuando fue abandonado a causa de una epidemia de viruela negra (Victoria, 2011, pp. 313, 320).

Como se ha visto, acerca del sitio únicamente existen las publicaciones de Robles y Andrews (2004), Restall (2009) y Victoria (2011). Desde los años que han pasado en que fueron escritos estos trabajos, el Archivo General del Estado de Yucatán (AGEY) ha puesto a disposición de los investigadores otra documentación, correspondiente al fondo Justicia y el fondo Poder Ejecutivo que permite conocer un poco más de aquel poblado y de quienes lo habitaron. La información obtenida en esas fuentes dio pauta para nuevas consultas a diversos acervos, como el Archivo Histórico de la Arquidiócesis de Yucatán, el Archivo de la catedral de San Carlos, Matanzas, Cuba, ${ }^{7}$ así como de otros documentos, en el propio AGEY y el Archivo Nacional de Cuba.

Con base a la nueva información se plantea como objetivos de estas líneas esclarecer en lo posible la proveniencia de los primeros pobladores de San Francisco de Paula, así como demostrar la existencia de relaciones entre ese rancho y el pueblo de San Fernando Aké, asuntos hasta ahora desconocidos, y que involucra a ambos sitios en su mayoría de afrodescendientes en Yucatán. Se propone como hipótesis que algunos de los primeros pobladores del rancho procedían de Cuba, aún bajo la administración colonial de España en el Caribe, ${ }^{8}$ expresamente de la región de Matanzas, quizá como gente libre; su número con exactitud se desconoce, aunque al menos siete personas se reportan primariamente en esa ínsula. Su arribo clandestino a las costas de Yucatán pudo ser a mediados de 1823 por el puerto de Nueva Málaga o un lugar cercano, para luego pasar al poblado de San Fernando Aké. Después de unos años en ese lugar, migraron de nueva cuenta para marchar al poniente del estado, donde fundaron San Francisco de Paula. Este hecho fue ocasión de una relación entre

\footnotetext{
${ }^{7}$ La consulta de esta documentación se realizó a través del Ecclesiastical and Secular Sources for Slave Societies (en adelante Essss), Nashville, Estados Unidos.

${ }^{8}$ Cuba se independizó de España después de luchas que duraron de 1868 hasta 1898.
} 
esos dos asientos (uno pueblo y el otro rancho), de vecinos afrodescendientes en Yucatán, inclusive con algún matrimonio entre gente de ambos sitios, aunque con el tiempo, a uno y otro llegaron residentes de diferente ascendencia.

Esta propuesta rebasa el marco de la historia regional y sitúa a Yucatán en el contexto de la historia del Caribe, reafirmando la relación entre la insularidad con la península a través de vínculos y migración de gente de origen africano. En ese sentido, Landers (2011, p. 242) señala que los negros libres que vivían alrededor de las fronteras marítimas españolas, por ejemplo, una isla (Cuba), buscaban cualquier oportunidad para encontrar actividades que les permitieran movilidad tanto social como geográfica. En el caso de los africanos y afrodescendientes que estaban en la Mayor de las Antillas, apunta que tenían conocimientos de la situación política, incluso de manera impresa, por lo que el contexto yucateco pudo ser de su dominio. ${ }^{9}$

Hechos como el aquí apuntado confirman a Yucatán como partícipe del llamado Caribe continental (como parte del Circuncaribe) ${ }^{10}$ y de las históricas relaciones pendulares entre el Caribe insular y el continental (Shrimpton, 2015) que para tiempos decimonónicos aún está falto de estudios en esa región mexicana. Del mismo modo, resulta de interés sacar a la luz el contacto que existió entre los dos asentamientos fundados por gente de ascendencia africana en la península, donde esa característica los identificó mutuamente.

\section{EL ARRIBO DESDE CUBA A YUCATÁN}

Los datos históricos con que se cuenta parecen apuntar que la gente en cuestión hizo su llegada a Yucatán por el puerto de Nueva Málaga, ubicado al noroeste peninsular, y que arribaron de forma ilegal. De tal manera que, el 30 de junio de 1823 se notificaba que, a sabiendas de la introducción de "negros bozales" ${ }^{11}$ por ese punto de la costa, el gobierno solicitaba se informe sobre

9 Bretones (2013) también considera que el Caribe era un espacio extremadamente dinámico, de rutas de comercio, de personas diversas y de noticias. Esa unidad hizo que las colonias y territorios se interconectaran con el constante flujo de personas y escritos noticiosos.

${ }^{10}$ Este concepto geográfico abarca todo el espacio que cubre las Antillas Mayores y Menores, además de las costas continentales de las cuencas marítimas del Golfo-Caribe (Von Grafenstein, 1997, p. 14).

${ }^{11}$ La palabra bozal, en términos académicos, refiere al africano recién llegado de su tierra y que no ha aprendido la lengua ni oficio alguno. En el contexto del tráfico ilegal y a partir de las ideas que intentaban proteger la propiedad privada sobre los esclavos adquiridos de manera no le- 
el o los lugares donde esa gente se localizaba, "y resultando que en efecto procedan del cargamento que apresaron en Nueva Málaga, se les asegure su sustento y educación por medio de los ayuntamientos". ${ }^{12}$ La nota deja ver que no fue escasa la gente que arribó a Yucatán.

Para julio siguiente, el subdelegado de Tizimín informaba al jefe superior político acerca de la existencia de "un número grande de negros" que se ocultaba en los montes de su jurisdicción. La Junta Superior Gubernativa recomendó al subdelegado que los buscase y remitiese a Mérida. ${ }^{13}$ Poco después, el Ejecutivo instó se le pregunte al jefe superior de Tizimín acerca de los avances de la anterior encomienda. En caso de no haberse llevado a cabo por alguna razón, la máxima autoridad le recomendaba ejecutarla a la brevedad con "resultados en favor de la humanidad interesada en esta providencia". ${ }^{14}$ En esta última frase es notorio el sentir y pensar político de ese momento hacia la esclavitud (a pesar de que posiblemente no tenían esa condición los recién llegados), la cual se prohibiría en su introducción en Yucatán poco después. Esta medida también puede responder a la preocupación de la autoridad de que algunas personas presentasen a aquella gente como antiguos esclavos en el estado, por lo que no alcanzarían la libertad.

La idea de cierto paternalismo humanitario también se refleja en el oficio del comandante de Nueva Málaga, Juan Acevedo, quien señaló que se

gal, se implantó un presunto significado jurídico del término, aplicable al africano que procediese de un desembarco inmediato hecho contra las leyes que prohibían el tráfico (Meriño y Perera, 2015, pp. 15-16). Ante el desconocimiento de su situación legal, la autoridad yucateca los señaló como bozales indicando con ello su desembarco clandestino, no alguna condición de esclavos.

${ }^{12}$ Despacho del 30 de junio de 1823. Fondo Congreso. Ramo Acuerdos. Vol. 1. Libro de acuerdos de la Junta Provisional Gubernativa, fs. 8-9. Archivo General del Estado de Yucatán (en adelante AGEY), Mérida, México. No se ha encontrado documentación que indique pistas sobre el cargamento arriba apuntado. Tampoco se sabe el mes exacto en que entraron a Yucatán ya que el Despacho citado señala el día cuando se tomó cartas en el asunto. El trato indicado hacia los recién llegados es indicio de una aceptación muy de acorde a los tiempos políticos en el Yucatán de 1823 en relación a la introducción de esclavos. En cuanto a la educación apuntada, es posible que ello esté relacionado a una aceptación en el poblado dado que implicaría una estancia en el sitio para hacerlas personas útiles.

${ }^{13}$ Despacho del 25 de julio de 1823. Fondo Congreso. Ramo Acuerdos. Vol. 1. Libro de acuerdos de la Junta Provisional Gubernativa, f. 15. AGEy, Mérida, México. En el Despacho del 8 de julio de 1823, f. 11v, se dice que un tal Tomás Osorio había llevado unas personas de apariencia africana a Mérida, y en Despacho del 5 de agosto de 1823, f. 17v, se solicitaba averiguar si de la gente introducida por Nueva Málaga no había alguna en Motul.

${ }_{14}$ Despacho del 9 de septiembre de 1823. Fondo Congreso. Ramo Acuerdos. Vol. 1. Libro de acuerdos de la Junta Provisional Gubernativa, f. 23. AgEy, Mérida, México. 
habían cometido "excesos con los negros" dispersos en los montes. Ante esos hechos se determinó que Acevedo quedase como responsable de recoger a los "bozales" y remitirlos a la capital, ${ }^{15}$ dado que el jefe político al parecer no le ponía empeño al asunto. Para esa tarea, sin conocerse la causa, se resistieron a participar Alonso Aznar y Miguel Molas. ${ }^{16}$ Este último era funcionario en el ramo de las armas y de la Real Hacienda, había sido comandante militar de Nueva Málaga en 1821 (Stephens, 1984, p. 293), ${ }^{17}$ hasta su destitución debido a los cambios consecuentes de la Independencia.

Después de presentar los datos anteriores, se propone que algunas personas que fueron introducidas por Nueva Málaga, después de estar por los montes, llegaron a San Fernando Aké, poblado de afrodescendientes en su mayoría.

La causa de la salida de esa gente de Cuba no es clara, sin embargo, el ambiente político-social en la región isleña de procedencia no era el más propicio para permanecer para los de ascendencia africana, aun siendo libres. Un panorama de la región matancera bosqueja que los años finales del siglo XVIII y las primeras décadas del XIX, fueron testigos del despegue y consolidación de la producción azucarera en esa zona, en concordancia, los esfuerzos de los grandes hacendados estuvieron enfocados en sostener y mantener, a como diese lugar, las relaciones de producción a través del trabajo forzado, lo que a la vez se reflejaban en rebeldías sociales, la existencia de palenques y cimarrronaje (Balboa, 2002, p. 50-53; Ruiz, 2001, pp. 11, 40). Asimismo, en parte de la temporalidad de la posible salida (1821-1823) se dio el movimiento denominado la conspiración "Rayos y Soles de Bolívar", la cual se extendió por las partes oeste y central de la isla, ${ }^{18}$ cuyo fin era proclamar la independencia y abolir la esclavitud, entre otros asuntos, y en el cual todo mundo resultaba sospechoso (Naranjo, 2017, p. 64). De igual manera, en 1823 se restableció el Absolutismo en España y sus territorios, lo que originó un mayor control social, y la pérdida del intento de abolir la esclavitud por medio de las Cortes españolas (García, 2005, pp. 329-331). Todo ello creó un ambiente

${ }^{15}$ Despacho del 11 de septiembre de 1823. Fondo Congreso. Ramo Acuerdos. Vol. 1. Libro de acuerdos de la Junta Provisional Gubernativa, fs. 23v-24. Agey, Mérida, México.

${ }_{16}$ Despacho del 17 de septiembre de 1823. Fondo Congreso. Ramo Acuerdos. Vol. 1. Libro de acuerdos de la Junta Provisional Gubernativa, f. 25. AgEy, Mérida, México.

${ }^{17}$ En Dificultades para la toma de Yucatán. 9 de septiembre de 1828. Fondo Asuntos Políticos, núm. de Orden 77. Archivo Nacional de Cuba (en adelante ANC), La Habana, se señala que el puerto fue fundado por Molas en 1821, lo que constituye un error.

${ }_{18}$ Matanzas se localiza en esta última parte de la isla. 
social y político donde las autoridades temían una conspiración de esclavos y del surgimiento del sentimiento abolicionista. Ese contexto llevaría a lo que Landers (2011, p. 256) señala como una situación de deterioro social en que se encontrarían los negros libres criollos con el avance de la problemática situación. Las condiciones, entonces, eran propicias para que saliese quien pudiese hacerlo, sobre todo, teniendo noticias mejores de otro lugar como destino.

Por otra parte, es posible que Miguel Molas haya tenido que ver en la introducción clandestina de esa gente de origen africano, dada la acusación posterior en su contra, como se señala más adelante, lo que se refuerza por su negativa a participar en la recogida de los africanos y afrodescendientes dispersos. La presunta participación de ese funcionario y posteriormente prófugo se apoya en su propio historial. El catalán Miguel Molas fue encargado de la vigía de El Cuyo en 1814, sitio que en la práctica era puerta para el contrabando (Farriss, 1992, p. 148; Victoria, 2015), y en 1821 fungió como comandante militar de Nueva Málaga (Stephens, 1984, p. 293). No obstante, con posterioridad formó parte de la red para el contrabando de géneros y de personas. Debido a sus acciones ilegales pasó a ser perseguido por el gobierno de Yucatán. En 1824 la autoridad estatal solicitó investigarlo sobre "la odiosa venta y embarque que ha hecho para la Habana de multitud de originarios de África" ${ }^{19}$ El suceso se trataba del reportado en enero de ese año cuando las autoridades meridanas supieron de una causa iniciada en Campeche por el tráfico clandestino de catorce negros desde Sisal, ${ }^{20}$ presumiblemente parte de los introducidos por Yalahau (antes Nueva Málaga), ${ }^{21}$ hecho en el cual Miguel Molas y Buenaventura León estaban involucrados, según el comandante Acevedo. ${ }^{22}$ Colateralmente a esa denuncia, también se le persiguió ya que se

${ }^{19}$ Libro de Sesiones Secretas del Augusto Congreso Constituyente. De 23 de agosto de 1823 a 18 de abril de 1833. Fondo Congreso. Ramo Acuerdos. Vol. 1, exp. 1, fs. 8v-9. AGEY, Mérida, Yucatán.

${ }^{20}$ Despacho del 16 de enero de 1824. Fondo Congreso. Ramo Acuerdos. Vol. 1. Libro de acuerdos de la Junta Provisional Gubernativa, f. 61. Agey, Mérida, México.

${ }^{21}$ Despacho del 22 de enero de 1824. Fondo Congreso. Ramo Acuerdos. Vol. 1. Libro de acuerdos de la Junta Provisional Gubernativa, f. 62. AgEy, Mérida, México.

${ }^{22}$ Despacho del 13 de febrero de 1824. Fondo Congreso. Ramo Acuerdos. Vol. 1. Libro de acuerdos de la Junta Provisional Gubernativa, f. 68. Agey, Mérida, México; Despacho del 23 de febrero de 1824. Fondo Congreso. Ramo Acuerdos. Vol. 1. Libro de acuerdos de la Junta Provisional Gubernativa, fs. 71-71v. AGEy, Mérida, México. 
hablaba que Molas apoyaría cualquier intento de invasión española a Yucatán desde Cuba. ${ }^{23}$

Para 1828 seguía la búsqueda de Molas, pues el subdelegado de Espita señalaba "no haberse podido averiguar lo cierto en el poblado de San Fernando del prófugo español”. ${ }^{24}$

La relación de esta persona con los pobladores de San Fernando Aké fue muy estrecha al grado que, al fallecer alrededor de 1840 en la costa oriental yucateca, su cadáver sería conducido a ese poblado, pero se perdió en el mar durante la travesía (Stephens, 1984, pp. 281-282, 323). Asimismo, en ese sitio residían sus dos hermanas Isabel y Manuela, apuntadas en el padrón de $1841 .{ }^{25}$

El contacto de Miguel Molas con vecinos de Cuba pudo no ser sólo de tipo comercial (gente o géneros), sino también de ayuda y colaboración entre parientes para facilitar sus actividades. En relación con esta idea, el 23 de junio de 1829 bautizó en Matanzas al niño Florencio Francisco, hijo de Buenaventura Molas, natural de Cataluña, y de Felicia B., parda libre, vecina de la región matancera. Su padrino fue don Félix Molas. ${ }^{26}$ Quizá fueron familiares y posibles colaboradores, pero no deja de ser suspicaz el hecho de que en ese sitio existiesen otros Molas, de Cataluña, y también uno con el nombre Buenaventura, al igual que los dos sujetos perseguidos en Yucatán. De Molas, para ese tiempo no se tiene noticias de familiares más allá de sus hermanas que vivían en San Fernando Aké.

A pesar de que las citas son claras en cuanto al sentido de la conducción de personas de apariencia africana desde Sisal a Cuba por parte de Molas, este pudo hacerlo también en sentido inverso: de la isla a la península. Miguel Molas tenía empatía (cuando no interés) por los afrodescendientes como en el caso de los habitantes de San Fernando Aké. Se plantea que Molas, tal vez

${ }^{23}$ Se dice que Molas proclamó y juró el gobierno monárquico en el pueblo de Yalahau (antes Nueva Málaga), a donde, según él, arribarían dos buques de Cuba para sostenerlo. Libro de sesiones secretas del Augusto Congreso Constituyente. Del 23 de agosto de 1823 al 18 de abril de 1833. Fondo Congreso del Estado. Ramo Sesiones. Vol. 1, exp.1, f. 16. AGEy, Mérida, México.

${ }^{24}$ Fragmento de un cuaderno copiador de oficios del gobernador José Tiburcio López con los jefes militares. Noviembre-diciembre de 1828 (20 de diciembre). Poder Ejecutivo. Ramo Correspondencia Oficial. Vol. 1, exp. 22. Agey, Mérida, México.

${ }_{25}$ Padrón general de los habitantes de Kikil y su comprensión, del partido de Tizimín, con expresión de sexos, edades y ocupación. San Fernando, mayo 12 de 1841. Fondo Poder Ejecutivo. Ramo Padrones. Vol. 3, exp. 27. AGEy, Mérida, México.

${ }^{26}$ Matanzas. Bautismos de Pardos y Morenos, 1826-1830. Libro 13, f. 277v. Essss, Nashville, Estados Unidos. 
por el cobro en el traslado, pudo sacar de Cuba a un grupo de personas, entre las que se encontrarían los que llegaron hasta el pueblo de afrodescendientes ya existente en Yucatán y, años más tarde, trasladarlos hacia la zona de Sisal, acompañados de otros individuos. ${ }^{27}$

Cierto que el planteamiento tiene sus debilidades ante la ausencia de más información que amalgame de mejor manera la hipótesis. Se cuenta con los datos de que algunas personas del rancho procedían de Cuba, pero no se tiene información segura acerca de su traslado a Yucatán. Queda entonces el recurso de especular en cuanto a la participación de Molas en ese hecho con base en sus antecedentes: introducción de contrabando por la vigía a su cargo, negativa a recoger a los "negros" llegados por Nueva Málaga, acusaciones de traslado y venta de gente africana a Cuba, familiares suyos en San Fernando Aké, gente con el patronímico Molas en Matanzas, y la consideración que tuvo la familia Molas en San Fernando. Estos aspectos hacen posible ver la propuesta como una respuesta tentativa, en espera de nuevos estudios que corrijan o apoyen las ideas vertidas.

\section{POBLADORES DE SAN FRANCISCO DE PAULA}

Los vestigios de este sitio se localizan a unos siete kilómetros al sureste del puerto de Sisal, Yucatán, México, justo detrás de la ciénega. ${ }^{28}$ La primera nota documental con la que se cuenta es una petición de sus moradores, denotando la calidad de ciudadanos en ejercicio de sus derechos, que proviene de $1837,{ }^{29} \mathrm{y}$ su ubicación aparece en un plano de 1845 (Antochiw, 1992, lámina 137).

${ }^{27}$ El contacto entre Yalahau (antes Nueva Málaga) y Sisal por vía marítima fue frecuente en el siglo XIX, ello fue ocasión para conocerse ambos sitios en los extremos del norte yucateco.

${ }^{28}$ En un momento de su historia el rancho se conformó de unos 28 solares de forma irregular, demarcados por albarradas, en los cuales existen muros de algunas casas y bodegas. El asentamiento cuenta con algunos callejones y abarcó una extensión tentativa de 300 x 400 metros (Robles y Andrews, 2004).

${ }^{29}$ El escrito de 1837 es una misiva de la Junta Departamental al gobernador de Yucatán, donde se señalaba la inconformidad de los "morenos" de ese rancho por el pago de la contribución personal, no obstante, se indicó que los solicitantes debían de hacer dicho desembolso ya que cumplían el requisito de estancia y porque obtenían una renta por su trabajo agrícola. Correspondencia de la Junta Departamental de Yucatán con el gobernador, del 17 de enero al 26 de junio de 1837. Ramo Correspondencia Oficial. Caja 9, vol. 6, exp. 9. AGEY, Mérida, México. La ley mencionada es la "Ley de arreglo del cobro de la contribución personal", del 23 de febrero de 1823 (Peón y Gondra, 1832, vol. II, pp. 213-214). La búsqueda de la misiva de los morenos en 
Un dato importante para una parte de nuestro objetivo proviene del sábado 27 de julio de 1844, cuando en la iglesia de Sisal se casaron "el moreno Hipólito Rivas, natural y bautizado en Matanzas en la isla de Cuba, siendo hijo legítimo de Nicolás ${ }^{30}$ y Úrsula Rivas, con Dorotea Rivas, natural y bautizada en el mismo sitio, hija legítima de Francisco y Laureana Rivas y vecinos del Rancho San Francisco de la conformación de esta capellanía". ${ }^{31}$ Los testigos de ese sacramento fueron "el moreno" Benito Rivas, José Rodríguez y Julián Dorantes. Fungieron como padrinos don Antonio Herrera y Rivas-Cacho y su esposa doña Inés Novelo. ${ }^{32}$ Dato similar se tiene con la fecha del 11 de abril de 1847 donde se indica que un tal Alejandro Rivas, natural y bautizado en Matanzas, Cuba, y viudo de Nestora Suárez, enterrada en el camposanto del Hospital de Mérida, ${ }^{33}$ solicitaba permiso para contraer matrimonio con la indígena Leonarda Cab, de Sisal. ${ }^{34}$ El dato del entierro puede inducir a que esa persona apellidada Rivas vivió un tiempo en la capital del estado. En el padrón de 1849 de San Francisco de Paula no aparece Hipólito, ${ }^{35}$ pero si se

el archivo no ha tenido éxito. La Constitución de Yucatán de 1825 les amparaba en cuanto a la obtención de la ciudadanía con el ejercicio de derechos y obligaciones. Para el caso véase, Constitución Política del Estado Libre de Yucatán, sancionada el 6 de abril de 1825. Recuperada de https:// archivos.juridicas.unam.mx/www/bjv/libros/7/3151/13.pdf

${ }^{30}$ En siguientes documentos es señalado como Pedro Rivas.

${ }^{31}$ Resulta de interés la mención de los padres en el bautizo en Cuba, pues refleja un conocimiento de los integrantes de la familia lo que, en parte, refuerza la idea de estado de libertad que tenían.

${ }^{32}$ Hunucmá. Matrimonios, 1842-1883. Vol. 36, f. s. d. Archivo General del Arzobispado de Yucatán (En adelante AGAY), Conkal, México. Para marzo de 1833 se reporta la presencia en Sisal de Antonio Herrera Rivas-Cacho, entonces de catorce años, y sus padres Cecilia y Antonio, Matrícula del puerto de Sisal hecho el 23 de marzo de 1833, con expresión de clases, oficios y edades. Caja 5, vol. 3, exp. 5. AgEy, Mérida, México.

${ }_{33}$ En los libros de defunciones del Sagrario y de la parroquia de San Cristóbal, se buscó sin éxito a la difunta Nestora Suárez. Por la temporalidad son las parroquias de más probabilidad de asiento del entierro.

${ }^{34}$ Hunucmá. Matrimonios, 1839-1884. Vol. 35, f. 56v. AgAY, Conkal, México. La ceremonia religiosa se realizó en la iglesia de Hunucmá el lunes 23 de abril de 1847. Los padres de la novia eran Apolinar Cab y Paula Colli, los testigos fueron Antonio Aguilar, Santiago Naal y Antonio Solís, "vecinos de este pueblo" (Hunucmá). Hunucmá. Matrimonios, 1939-1884. Vol. 34, f. 148v. AGAY, Conkal, México. No hubo testigo de apellidos Rivas.

${ }^{35} \mathrm{Al}$ menor desde 1841 se le encuentra viviendo en Sisal. Padrón general de habitantes del pueblo de Hunucmá y su comarca de haciendas, sitios y ranchos. Fondo Poder Ejecutivo. Ramo Censos y padrones. Caja 39, vol. 2, exp. 22. También aparece años después en el rancho. Causa instruida contra Camila Sandoval por el delito de incendio perpetrado en el rancho San Francisco de la jurisdicción de Sisal. 1 de marzo de 1853. Sisal. Fondo Justicia, 1821-1913. Serie penal. Sección Juzgado de Primera Instancia de lo Criminal. Subserie Incendio. Caja 67, vol. 
reporta a un Alejandro Rivas, de 26 años, casado, presuntamente la misma persona desposada.$^{36}$ La procedencia desde la isla antillana de una parte de los habitantes del rancho queda comprobada con las actas apuntadas, sin embargo, no se sabe cuántos arribaron a Yucatán.

De estas notas hay que subrayar que únicamente se utiliza la ya oficialmente extinta denominación de "moreno" ${ }^{37}$ para señalar a Hipólito Rivas y a Benito Rivas, uno de sus testigos de matrimonio, no así para la contrayente y sus padres, al igual que para Alejandro Rivas, que se omitió quizá únicamente por descuido del cura de la parroquia, o para indicar, a través de ese eufemismo apuntado a uno de ellos, la procedencia africana/foránea de los Rivas, a pesar de ser residentes en Yucatán.

Con base en la mención de que algunos primarios pobladores del rancho fueron bautizados en Matanzas, se plantea que nunca trabajaron en la región peninsular en estado de esclavitud, como apunta la tradición oral. Sostenemos que al darse su arribo por Nueva Málaga poco antes de lo dictado sobre la introducción de esclavos por el Congreso yucateco en 1823, ante la duda de su situación en la Cuba colonial, pudieron quedar comprendidos en el beneficio de la libertad. ${ }^{38}$ En concordancia con lo señalado por el Poder Ejecutivo el 9 de septiembre de ese año, en cuanto a que se recoja a los africanos y afrodescendientes dado que era un mandato "en favor de la humanidad interesada en esta providencia”, se deja ver la voluntad política de integrar a esos inmigrantes en el marco jurídico de libertad por estar en suelo yucateco y otorgarles esa gracia. Ese gesto de las autoridades se enmarca en la prohibición por mandato del arribo de esclavos, efectuado pocos días después.

Si la gente que arribó a Yucatán era libre en Cuba, es muy probable que tuviese conocimiento, tal como apunta Landers (2011), del ambiente políti-

67, exp. 2. AGEy, Mérida, México. Su esposa vivía en el rancho y quizá también tenía una casa en Sisal.

${ }^{36}$ Padrón general de los habitantes del puerto de Santa María de Sisal y su comprensión, rancho de San Francisco de Paula y Celestún. 1849. Fondo Poder Ejecutivo, 1843-1885. Sección. Censos y Padrones. Caja 64, vol. 14, exp. 49. Agey, Mérida, México.

${ }^{37}$ A pesar de que en 1822 se prohibió el uso de clasificar a los individuos a partir de "castas" o calidades, la práctica continuó en ciertos espacios, sea por costumbre o sentido peyorativo. Por ejemplo, en 1837 las autoridades mencionan a los pobladores del rancho en cuestión como "morenos". Correspondencia de la Junta Departamental de Yucatán con el gobernador, del 17 de enero al 26 de junio de 1837. Ramo Correspondencia Oficial. Caja 9, vol. 6, CD. 8. AGEY, Mérida, México.

${ }^{38}$ Ese suceso aconteció mientras México y España estaban en guerra por la situación de los primeros en San Juan de Ulúa, Veracruz. 
co propicio en la península como destino. Allí encontrarían una atmósfera con reglamentaciones ajenas al sistema esclavista y su condición de libres, y amparados en lo jurídico, les daba posibilidad de ascenso social. Esa autora retoma el concepto de "alfabetización geopolítica", de Phillip Troutman, que incide en el aprendizaje por medio de la comunicación oral y escrita. ${ }^{39}$ Los migrantes seguro sabían de San Fernando Aké, conformado por gente afrodescendiente salida de Haití, y de los huidos de Wallix (Belice) que a ese poblado llegaban, y tiempo después, sin duda, otros en Cuba sabrían de las condiciones políticas y jurídicas existentes en la región. ${ }^{40}$

En México, la abolición de la esclavitud fue un tema de importancia desde la insurgencia de Miguel Hidalgo en 1810, pasando por José María Morelos, hasta el surgimiento de la incipiente nación mexicana, en 1824 (Herrera, 1991, p. 19; Olveda, 2013, pp. 11-14). En Yucatán, el Primer Congreso Constituyente del Estado prohibió el 13 de septiembre de 1823 la introducción de personas en estado de esclavitud, declaró la libertad de los hijos de aquellos existentes en el estado, así como la posibilidad de otorgar la libertad a los esclavos, previo consentimiento de sus amos y manumisión, sin que por ello se detuviese el comercio de los ya existentes en esas tierras (Peón y Gondra, 1832, vol. I, pp. 37-38). La Constitución yucateca de 1825 recogió la anterior prohibición de ese tráfico inhumano, y lo relativo a los esclavos existentes en el estado. ${ }^{41}$ El 15 de septiembre de 1829, el presidente de México, Vicente Guerrero, emitió un decreto para la liberación de los esclavos, cuya valoración sería resarcida por el erario, cuando fuese posible (Olavarría y Arias, 1972, vol. IV, p. 214). En consecuencia, el 12 de octubre de 1829 en Yucatán se expidió

${ }^{39}$ La "alfabetización geopolítica" engloba los conocimientos políticos, sociales, la destreza lingüística, la facilidad de adaptación, el saber de otros lugares, etc., que adquirieron los africanos y afrodescendientes a través de la comunicación oral y escrita (Landers, 2011, p. 242).

${ }^{40} \mathrm{Al}$ darse en 1844 la represión conocida como la matanza de La Escalera, centenares de personas libres consideradas de origen africano fueron obligadas a salir de la isla (Landers, 2011, pp. 256-257). Varios de esos emigrados llegaron a tierras yucatecas. Al menos eso puede pensarse de la petición del cónsul español al gobierno de México acerca de que regrese a Cuba la gente que salió de la isla. México alegó que habían salido con pasaporte en regla y mandó a aquella se retirase al menos diez leguas de la costa y que se interne a los pueblos del interior. El ministro de Relaciones Exteriores comunica al gobernador de Yucatán acerca de que los negros y mulatos que existen en las costas de Yucatán retornen a la isla de Cuba. México, 1846. Fondo Poder Ejecutivo. Correspondencia Oficial. Caja 75, vol. 25, exp. 2, CD. 39. AGEY, Mérida, México.

${ }^{41}$ Constitución Política del Estado Libre de Yucatán, sancionada el 6 de abril de 1825. Recuperada de https://archivos.juridicas.unam.mx/www/bjv/libros/7/3151/13.pdf 
un Reglamento para la liberación de los esclavos, estableciendo en él la realización de un avalúo de los bienes que perdería el dueño, entregando a este un vale que cobraría posteriormente (Ruz, 1970, p. 12). Por último, en 1837 se abolió la esclavitud en todo el territorio nacional (Delgadillo, 2019, p. 748).

De manera cronológica, el siguiente documento sobre San Francisco de Paula es un padrón levantado el 18 de abril de 1849, donde se reporta la presencia de 47 personas en el "Rancho San Francisco de Paula". En él se destaca que 18 varones y quince mujeres llevan el apellido Rivas, o sea, un total de 33 personas (70.21\%). Los restantes apellidos con una persona asentada, para el caso de los hombres, eran Mora, Campuzano, González, Caos, Gómez, Rodríguez, y Fernández. En cuanto a las mujeres, cuatro tenían el apellido Rodríguez, y una el de Cosgaya. ${ }^{42}$ No se registró ninguna persona como indígena en el padrón.

De todos los hombres, el de más edad era Timoteo Rivas que contaba con 90 años; cuatro tenían de 60 hasta 70 años; en la curva de los 50 a los 59 años había dos; de los 40 a los 49 años había dos; una persona contaba con 32 años; diez personas tenían entre 20 y 29 años, y uno más contaba con 17 años. La lista se completaba con la mención de cuatro menores de edad, de 1 a 13 años, destacando uno de ellos con la mención de "Negrito", en el espacio de "Estado" (civil). ${ }^{43}$ De nueva cuenta, la utilización de una calidad socio-racial supuestamente ya en desuso o el rasgo fenotípico para destacar a una persona entre las otras, obliga a la pregunta si esa "otredad" se utilizaba de manera inconsciente como resabio, o la mirada hacia ese grupo por parte de los funcionarios yucatecos que levantaron el padrón era para referirla como gente ajena en origen a la región.

Volviendo a ese documento, en el listado de hombres se encuentran siete casados, doce solteros, y dos viudos. Como ocupación, todos los mayores de once años, incluido Timoteo Rivas, son señalados como labrador. ${ }^{44}$

${ }^{42}$ Padrón general de los habitantes del puerto de Santa María de Sisal y su comprensión, rancho de San Francisco de Paula y Celestún, 1849. Fondo Poder Ejecutivo, 1843-1885. Sección, Censos y Padrones. Caja 64, vol. 14, exp. 49. Agey, Mérida, México.

${ }^{43}$ Si supuestamente todos, o casi todos, eran afrodescendientes, resulta extraño que a un menor se le denominase de aquella manera, como si fuese un sujeto con apariencia ajena al resto de los pobladores del asentamiento.

${ }_{44}$ Padrón general de los habitantes del puerto de Santa María de Sisal y su comprensión, rancho de San Francisco de Paula y Celestún, 1849. Fondo Poder Ejecutivo, 1843-1885. Sección. Censos y Padrones. Caja 64, vol. 14, exp. 49. Agey, Mérida, México. 
Por el lado femenino, las edades en promedio eran menores que las del otro género. Esas estaban encabezadas por Marcelina Rivas con 48 años, más otras tres que contaban con algo más de cuatro décadas de vida; de entre 30 a 39 años había seis mujeres; de 20 y máximo de 29 había dos personas; de catorce años, al parecer la mayoría de edad, y de menos de 20 años había cuatro personas. Las menores de edad eran seis, siendo Victoriana Rivas, con nueve meses de nacida, la más pequeña de la comunidad. ${ }^{45}$ De todas ellas, únicamente tres se señalan como casadas, mientras que la mayoría, doce, eran solteras. Sólo se reporta una viuda.

En el registro el término "casada" pudo no incluir a las relaciones consensuadas, ya que sólo aparecen tres casadas. Sin embargo, siguiendo un estricto significado legal, todas las madres solteras y las mujeres que vivían en uniones ilegales aparecen en los registros de la época como solteras (Arrow, 1988, p. 139). En San Francisco de Paula, Mónica Rivas es ejemplo de las solteras con descendencia, ya que llevó a bautizar a sus hijos ilegítimos el 12 de marzo de 1846 (Leandro Rivas); el 19 de diciembre de 1847 (José Viviano Rivas); el 11 de agosto de 1851 (Mariano Rivas), y el 12 de octubre de 1864 (María Mercedes). ${ }^{46}$

En el padrón del rancho de 1849 hay cinco hombres de apellido Rivas que por edad pudieron estar en el grupo originario de migrantes en 1823, aunque es posible agregar a Alejandro Rivas que pudo contar con pocos meses de nacido en ese año. De las mujeres hay ocho personas que pudieron hacer el viaje en 1823, aunque también se puede agregar a una más con 26 años pensando que, al igual que Alejandro, sería una infanta de meses. La suma de ambos es de trece adultos y dos niños de pecho.

Si Hipólito Rivas y Alejandro Rivas dijeron haber sido bautizados en la catedral de San Carlos de Matanzas, una revisión a la documentación de ese sacramento elaborada en aquella iglesia arrojó su inexistencia a la vez que el apellido Rivas únicamente aparece dos veces en todos esos años, ${ }^{47}$ lo que indica que no fueron asentados en la catedral, o que la información proporcio-

${ }_{45}$ El 16 de diciembre de 1882, Felipe Morales, soltero, "bautizado en San Juan Bautista de Tabasco", y vecino de Sisal, señaló su pretensión de matrimonio con Victoriana Rivas, la menor en el padrón de 1849, hija de Adelaida Rivas. Hunucmá. Matrimonios, 1842-1884. Vol. 37, f. s. d. AGAY, Conkal, México.

${ }^{46}$ Hunucmá. Bautizos, 1842-1868. Vol. 34, fs. 25, 3v., 75v., y 168. AGAY, Conkal, México.

47 Véase, Matanzas. Bautismos de Pardos y Morenos. 1823-1830. Libro 11. Essss, Nashville, Estados Unidos. 
nada estuviese errada. Cabe apuntar que, al casarse en Sisal los desposados no mostraban documento que avale la procedencia, únicamente se confiaba en la palabra de los contrayentes y la de los testigos, por lo que la verdad pudo ser alterada.

De acorde con la documentación de los matrimonios en el puerto de Sisal, se piensa que de Cuba salieron, al menos, Hipólito y Alejandro, Pedro y Úrsula; Dorotea y sus padres Francisco y Laureana Rivas, ${ }^{48}$ o sea, siete personas (cuatro hombres y tres mujeres). ${ }^{49}$ Con base en el padrón de 1849 , si se les quita 26 años a las edades señaladas, para 1823 (llegada por Nueva Málaga) los padres de Hipólito, Pedro y Úrsula, tendrían 35 y doce años, respectivamente.

Acorde a lo anterior, la propuesta es que, al menos, siete personas vinieron de Cuba, y que serían de los primeros pobladores del rancho. Pudieron ser más, pero la ausencia de información para esos años impide especular en cuanto al número. A esa cantidad se le puede sumar la presencia de Eugenio Duarte, quien aparece en la documentación años más tarde. Ante la duda es preferible utilizar al número en cuanto a los apellidados Rivas (siete).

En la tradición oral recopilada en Sisal y Hunucmá se dice que los pobladores del rancho llegaron huyendo de la esclavitud desde la región de Cayal, ayudados por una persona de apellido Duarte (Victoria, 2011), lo que apuntaría a la posible procedencia del grupo mayoritario desde el actual estado de Campeche. Aunado a lo oral, ese patronímico entra a esta historia el día 26 de marzo de 1858, fecha en que compareció Eugenio Duarte, quien señaló ser natural de La Habana, vecino del rancho San Francisco, y dijo pretender casarse con Caciana Ek, natural del mismo rancho, presentando como testigos a José María Campusano, Esteban Rivas y a Antonio Delgado. ${ }^{50}$ Esa persona fue padre de Bernavel Duarte, quien presuntamente nació también en 1858, según consta en el acta de su fallecimiento, acontecido el 8 de septiembre de 1936. Este sujeto fue uno de los últimos habitantes del sitio de que se tenga noticia, antes de su abandono por la viruela, alrededor de 1916,

48 Para 1846 Laureana Rivas es señalada en el nacimiento de uno de sus nietos. Hunucmá. Bautizos. 1842-1868. Vol. 34, f. 26. AGAY, Conkal, México.

49 Para julio de 1823 se apunta que un tal Diego Páez había conducido a Sisal a siete negros de los introducidos por Nueva Málaga, y que los retenía en una casa. Despacho del 1 de julio de 1823. Fondo Congreso. Ramo Acuerdos. Vol. 1. Libro de acuerdos de la Junta Provisional Gubernativa, f. 10. AGEY, Mérida, México. La cifra coincide más no se piensa que son las personas en cuestión.

${ }^{50}$ Hunucmá. Matrimonios, 1842-1884. Vol. 37, f. 50v. AGAY, Conkal, México. 
cuando parte de los moradores se reubicaron en Sisal, y que la memoria oral lo refiere como "negro" (Victoria, 2011, pp. 313, 320).

A pesar de que no se señala, Eugenio Duarte fue afrodescendiente; se desconoce su edad al momento de presentar sus intenciones matrimoniales, así como si pertenecía al grupo originario de arribo. En caso de haber llegado también en 1823 contaría, al menos, con 35 años. Su señalada procedencia habanera y su ausencia en el padrón de 1849 inducen a pensar en su llegada con posterioridad.

Los relatos orales acerca de la presunta ayuda prestada por Duarte han dado origen a una leyenda sobre su participación ya que se le asigna un destacado papel de colaboración para los que huían de la esclavitud antes de 1829, desde las fincas de la región de Cayal. Sin embargo, Duarte, aparece en San Francisco de Paula hasta 1858, casi tres décadas después de la emancipación de la esclavitud de 1829.

La nota petitoria de Duarte también es significativa dado que apunta que en el asentamiento ya vivía gente de otro grupo de identidad no afrodescendiente. La mención de que la mujer de procedencia maya, Caciana Ek, era residente de San Francisco de Paula es ejemplo de la apertura ya existente en el poblado, a la aceptación de una diversidad étnica, a la transculturación de saberes y, por supuesto, a la descendencia afro-maya.

\section{LOS RIVAS: UNA INTERROGANTE POR RESPONDER}

Es llamativo que en el padrón de 1849 un alto porcentaje de los habitantes de San Francisco de Paula llevasen el apellido Rivas. Dado el nulo resultado de la búsqueda en los registros de bautismos de la catedral de Matanzas, se plantea que ese patronímico puede provenir de los Rivas existentes en San Fernando Aké, donde se registran algunos vecinos con ese apellido (Pedro, de 80 años, uno de los mayores del asentamiento; José, de 30 años y Nicolasa, de doce años), y otros que habían adoptado el compuesto de Rivas Vertis (con s no z). ${ }^{51}$ En el segundo caso, no se sabe la causa por la que tomaron los apellidos del militar don Juan Rivas Vértiz. Esta persona destacó en la política en la prime-

${ }^{51}$ Padrón general de los habitantes de Kikil y su comprensión, del partido de Tizimín, con expresión de sexos, edades y ocupación. San Fernando, mayo 12 de 1841. Fondo Poder Ejecutivo. Ramo Padrones. Vol. 3, exp. 27. AgEy, Mérida, México. 
ra y segunda décadas de 1800, llegando a ser jefe político de Yucatán para 1820 (Ferrer, 2002, p. 133). A pesar de la laguna informativa que impide conocer la toma o préstamo de los apellidos, en San Fernando Aké se reporta a Luis (60 años) y a Serafina Rivas Vértiz (59 años), quienes debieron de recibir o adoptar esos apellidos en tiempo del militar. Los restantes Rivas Vértiz con base en la notificación en 1841 de San Fernando Aké, eran Joaquín (16 años) y Narcisa (catorce años). ${ }^{52}$ Se desconoce si alguno de los mayores de edad tenía alguna preeminencia que diese ocasión para copiar el apellido. En cuanto a los llegados de Cuba en 1823, bien pudieron adoptar el patronímico debido a alguna ayuda prestada por parte de los Rivas de San Fernando Aké.

En relación con la estancia de los arribados a este último poblado, cabe apuntar que Landers (2011, pp. 253-255) incluye a las tropas negras (libres por las armas) auxiliares de Carlos IV como uno de los medios de divulgación del ambiente político que posibilitaron la interconexión entre las regiones fronterizas del Caribe ya que fueron enviadas a diversas partes del continente americano. Uno de esos grupos en que fue dividida la tropa de Jean François, líder de origen africano de los mencionados auxiliares del rey hispano, fue remitido a Yucatán donde fundó San Fernando Aké en 1796 (Victoria y Canto, 2006). Las tropas procedentes de Saint-Domingue, diseminadas desde La Habana, y la constatada comunicación entre algunos de esos grupos, es muestra de una conexión y movimiento entre los africanos y afrodescendientes, asunto que posibilitaba la transferencia de noticias.

Por otra parte, el traslado a otro sitio (San Francisco de Paula) pudo responder a rencillas internas que existían. Por ejemplo, cuando en 1825 en San Fernando Aké se integró un piquete de la Milicia Activa con gente del sitio, estuvo a la cabeza del mismo Manuel Yuste. El 30 de mayo de 1826, Yuste ordenó a la patrulla trasladarse al no lejano pueblo de Sucopo, pero corrió el rumor de que en verdad los enviarían a Cuba; ${ }^{53}$ ante ello nueve de los soldados desertaron, dirigiéndose a la costa abordaron la canoa de un tal Nicolás (Miguel i?) Molas y regresaron al pueblo hasta el mes de julio siguiente. ${ }^{54} \mathrm{El}$ oficial mulato Yuste mandó que los huidos fuesen encarcelados y al no tener

${ }^{52}$ Padrón general de los habitantes de Kikil y su comprensión, del partido de Tizimín, con expresión de sexos, edades y ocupación. San Fernando, mayo 12 de 1841. Fondo Poder Ejecutivo. Ramo Padrones. Vol. 3, exp. 27. AgEy, Mérida, México.

${ }_{53}$ El rumor pudo ser por la venta de gente a los esclavistas de Cuba.

${ }^{54}$ Fondo Poder Ejecutivo. Ramo Milicia. Vol. 3, exp. 25. Agey, Mérida, México; Victoria y Canto (2006, p. 75). 
dinero para pagar el flete de la canoa, mandó azotar a uno de ellos -Antonio Dambrón-, y estando los desertores en el cepo los insultó y ofendió a sus esposas, padres y abuelos. Yuste fue acusado ante las autoridades por ese abuso, pero fue absuelto de castigo. ${ }^{55}$

Quizá ese tipo de problemas internos pudo ser el motivo para que más tarde gente de ese sitio decidiese trasladarse a otra parte. Se insiste en que la fundación de San Francisco de Paula y el periplo de un grupo de gente de un extremo a otro de Yucatán se debió de realizar a inicios de 1830, dado que, como apunta Victoria (2011), no se notifica la existencia del asiento en el plan de reconquista de México de 1828-1829 desde Cuba, a pesar de que se proponía iniciar la invasión entre los poblados de Sisal y Chuburná, incluso menciona el paso por la ciénaga. En ese plan únicamente se apunta a San Fernando Aké..$^{56}$

\section{INCENDIO EN EL RANCHO, OCASIÓN DE INFORMACIÓN Y DE LA RELACIÓN ENTRE LOS DOS POBLADOS}

Otra documentación novedosa para la historia del sitio lo constituye un expediente acerca de un incendio en San Francisco de Paula y la información generada a propósito de la averiguación. En él se apunta que el 1 de marzo de 1853 se presentó en la villa de Sisal Esteban Rivas, alcalde auxiliar suplente ${ }^{57}$

${ }^{55}$ Fondo Poder Ejecutivo. Ramo Milicia. Vol. 4, exp. 2. Agey, Mérida, México. Uno de los ancianos agraviados por Yuste fue el antiguo coronel de los auxiliares de Carlos IV, Ambrocio (Sasy) Plácido. Sobre establecimiento de negros auxiliares de Santo Domingo. Estado. Leg. 24, núm. 53. Archivo General de Indias (en adelante AGI), Sevilla, España.

${ }^{56}$ En el plan de reconquista de México, de Juan José Gora (1828-1829), se menciona la existencia de "los negros" de San Fernando Aké. Gora aseguraba haber vivido en Yucatán por 24 años y fundamentaba lo asentado en el plan en el conocimiento que tenía de Yucatán. En su plan Gora no mencionó a San Francisco de Paula. Dificultades para la toma de Yucatán. 9 de septiembre de 1828. Fondo Asuntos Políticos. Leg. 33, núm. de Orden 77. ANC, La Habana; Dificultad que puede pulsarse para formar una expedición que se apodere de la Provincia de Yucatán. 29 de octubre de 1828. La Habana. Fondo Asuntos Políticos. Leg. 33, núm. de Orden 77. ANC, La Habana.

${ }^{57}$ La existencia de esas autoridades en el rancho se basa en la Constitución yucateca de 1825, en un decreto y en una orden aclaratoria del 6 de mayo, que indica: "El gobierno político de las pequeñas poblaciones comprendidas en la comarca de los pueblos que tiene ayuntamiento o Juntas Municipales, y estén situadas a alguna distancia de ellos, estarán preventivamente a 
del rancho San Francisco de Paula, para notificar ante el alcalde primero del lugar, que el 19 de febrero se había quemado en el citado rancho un gallinero en la casa de Pedro Rivas, alcalde del sitio, y un cesto de ropa en el interior en aquella morada, en el que resultaba sospechosa la nuera del afectado, Camila Sandoval. Agregó el denunciante que el día 21 del mismo mes, estando en la "placita" del sitio en compañía de Pedro Rivas, Antonio Delgado, Estanislao y José María Campusano, se acercó la esposa del primero, de nombre Úrsula Rivas, diciendo que su nuera había soñado que se quemaría la iglesia del rancho, al igual que la casa de Pedro y la de Hipólito Rivas, suegro y cuñado de Sandoval, respectivamente. ${ }^{58}$

Apuntó que en esa fecha comenzó el fuego en casa de Hipólito y denunció que Camila pudo estar involucrada ya que poco antes se presentó a pedir una batea a Dorotea Rivas, esposa de quien sufrió el daño, y que luego del incendio descubrieron una braza de carbón entre el guano ya quemado que retiraron, la cual sospecharon que Camila habría llevado. ${ }^{59}$

A raíz de los sucesos, y como todos los varones salían al monte a trabajar, se decidió dejar a una persona de guardia en el rancho. A pesar de ello, el último día de febrero Hermenegildo Borges fue el encargado de aquella tarea (quien no aparece en el padrón de 1849); al medio día empezó a arder la casa de Pedro Rivas y la iglesia que estaba contigua. Borges declaró a los vecinos que instantes antes vio a Camila pasar por el lugar. La autoridad del rancho puso a disposición de su homónima de Sisal a Camila y a Hemeregildo. Ante la sospecha, se mandó detener a Sandoval y enviarla al calabozo de la antigua fortificación colonial de ese puerto. ${ }^{60}$

cargo de un alcalde auxiliar nombrado por el ayuntamiento o la Junta Municipal en su caso, y sujeto a las órdenes de los alcaldes constitucionales o conciliadores, residentes en la cabecera", Rodríguez (1985, vol. II, pp. 38-39).

${ }^{58}$ Causa instruida contra Camila Sandoval por el delito de incendio perpetrado en el rancho San Francisco de la jurisdicción de Sisal. 1 de marzo de 1853. Sisal. Fondo Justicia, 1821-1913. Serie penal. Sección Juzgado de Primera Instancia de lo Criminal. Subserie Incendio. Caja 67, vol. 67, exp. 2. AGEy, Mérida, México.

${ }^{59}$ Causa instruida contra Camila Sandoval por el delito de incendio perpetrado en el rancho San Francisco de la jurisdicción de Sisal. 1 de marzo de 1853. Sisal. Fondo Justicia, 1821-1913. Serie Penal. Sección Juzgado de Primera Instancia de lo Criminal. Subserie Incendio. Caja 67, vol. 67, exp. 2. Agey, Mérida, México.

${ }^{60}$ Causa instruida contra Camila Sandoval por el delito de incendio perpetrado en el rancho San Francisco de la jurisdicción de Sisal. 1 de marzo de 1853. Sisal. Fondo Justicia, 1821-1913. Serie Penal. Sección Juzgado de Primera Instancia de lo Criminal. Subserie Incendio. Caja 67, vol. 67, exp. 2. AgEy, Mérida, México. 
En el proceso judicial se tomó declaración a varias personas vecinas y no de San Francisco de Paula, cuya información permite conocer más acerca del poblado, de su gente, actividades y relaciones allende sus límites y con San Fernando Aké. Así, Pedro Rivas apuntó que en el incendio del cesto de ropa se le había quemado "un traje de Mayor que el cual [sic] también se había comprado a saber". Al parecer se estaría hablando de un traje militar que recuerda la organización castrense interna existente en San Fernando Aké y que sus autoridades importaron de Saint-Domingue. ${ }^{61}$ En el caso de San Francisco de Paula no hay datos que orienten hacia la existencia de esa formación de autoridad.

Aunque no aparece en el padrón del rancho de 1849, para la fecha del incendio mencionado, era vecino del sitio un tal Antonio Delgado, apuntado como soltero, de 53 años. ${ }^{62}$ En su declaración se dijo que era español, de 70 años, casado, sin saber firmar. Este dato indica que el rancho, en ese tiempo, no era en su totalidad de vecinos afrodescendientes. ${ }^{63}$

De la declaración de José María Campo (Campusano en el padrón), se deduce que en ese entonces no vivía en San Francisco de Paula, a pesar de aparecer en el registro de 1849, pues declaró haber ido al rancho a abonar una cantidad de dinero a Antonio Delgado por algún negocio de una casa entre ellos, y que después de los acontecimientos marchó para su rancho. No se sabe si era afrodescendiente. A propósito de ello, se advierte cierta movilidad de personas de San Francisco de Paula a otro sitio pues en el padrón

${ }^{61}$ En San Fernando Aké el régimen militar en la organización del grupo originario de 1796 perduró quizá hasta su desaparición en 1848 (Victoria y Canto, 2006, pp. 77-78). La presencia de ese uniforme militar es prueba de un elemento copiado de San Fernando, lo que refuerza la idea del contacto entre esos dos sitios.

${ }^{62}$ Padrón general de los habitantes del puerto de Santa María de Sisal y su comprensión, rancho de San Francisco de Paula y Celestún, 1849. Fondo Poder Ejecutivo, 1843-1885. Sección. Censos y Padrones. Caja 64, vol. 14, exp. 49. Agey, Mérida, México. En el padrón hay un Antonio de Caos. Puede tratarse de un error en el padrón ya que Delgado fue uno de los testigos en el matrimonio entre Camilo Rivas y Camila Sandoval el 2 de octubre de 1848, y se indicó en el acta que "todos eran vecinos" del rancho. Hunucmá. Matrimonios. 1842-1883. Vol. 36, f. 10. AGAY, Conkal, México. En el padrón de Sisal del año 1849 también aparece un tal Antonio Delgado como vecino de ese puerto. Padrón general de los habitantes del puerto de Santa María de Sisal y su comprensión, rancho de San Francisco de Paula y Celestún, 1849. Fondo Poder Ejecutivo, 1843-1885. Sección. Censos y Padrones. Caja 64, vol. 14, exp. 49. AGEy, Mérida, México.

${ }^{63}$ Causa instruida contra Camila Sandoval por el delito de incendio perpetrado en el rancho San Francisco de la jurisdicción de Sisal. 1 de marzo de 1853. Sisal. Justicia, 1821-1913. Serie Penal. Sección. Juzgado de Primera Instancia de lo Criminal. Subserie Incendio. Caja 67, vol. 67, exp. 2. Agey, Mérida, México. 
de Sisal de 1841, como se ha adelantado, se registra a Hipólito Rivas, de 25 años, casado, labrador ${ }^{64}$ De regreso al juicio, el 2 de marzo tocó declarar a la presunta culpable Camila Sandoval, que se dijo de 15 años (aunque en el padrón aparece de 17), esposa de Camilo Rivas. ${ }^{65}$ Ella aporta datos que ayudan a profundizar en el estudio del rancho y del vínculo entre los dos poblados de afrodescendientes mencionados en estas líneas. Sandoval declara que era natural del pueblo de San Fernando (Aké), y vecina de San Francisco de Paula por estar casada con uno de sus habitantes. ${ }^{66}$ La procedencia de Sandoval es de interés ya que indica contacto entre aquellos dos poblados yucatecos mayoritariamente de afrodescendientes.

Camila Sandoval aparece en el padrón de San Fernando Aké de 1841, apuntada como una menor de seis años; otra infanta señalada es Nolverta Rodríguez, de cuatro años. ${ }^{67}$ En el documento de 1849 de San Francisco de Paula se indica la presencia de Camila Rodríguez, de 17 años, casada, aunque, sin duda, es la misma persona. También aparece Nolverta Rodríguez, a quien se le apunta como de catorce años y soltera. ${ }^{68}$ En su declaración Camila hizo referencia a su "hermanita", con el nombre de Refugio Sandoval, no como Nolverta (a veces señalada como Rodríguez y en otras como Rodríguez Sandoval, al igual que ella), a su madre Isabel Rodríguez y una sirvienta a su servicio, de 23 años, del mismo nombre que la progenitora, todas ellas procedente de San Fernando Aké. ${ }^{69}$ En el listado de San Francisco de Paula se menciona a

${ }^{64}$ Tampoco está en el de 1849 pero se le encuentra en el tiempo del incendio.

${ }^{65}$ En el acta de matrimonio de Camilo y Camila, se indica al primero como hijo natural de Úrsula Rivas, no se menciona a Pedro Rivas. Hunucmá. Matrimonios, 1842-1883. Vol. 36, f. 10. AgAY, Conkal, México.

${ }^{66}$ Causa instruida contra Camila Sandoval por el delito de incendio perpetrado en el rancho San Francisco de la jurisdicción de Sisal. 1 de marzo de 1853. Fondo Justicia, 1821-1913, Serie Penal, Sección Juzgado de Primera Instancia de lo Criminal, Subserie Incendio. Caja 67. Vol. 67, exp. 2. Archivo General del Estado de Yucatán, Mérida. Véase también, Hunucmá. Matrimonios, 1842-1883. Vol. 36, fs. 9v-10. AGAY, Conkal, México.

${ }^{67}$ Padrón general de los habitantes de Kikil y su comprensión, del partido de Tizimín, con expresión de sexos, edades y ocupación. San Fernando, mayo 12 de 1841. Fondo Poder Ejecutivo. Ramo Padrones. Vol. 3, exp. 27. AGEy, Mérida, México. Damos por sentado que todas esas personas eran afrodescendientes, aunque, por razones de prohibición, el padrón no lo indique.

${ }^{68}$ Causa instruida contra Camila Sandoval por el delito de incendio perpetrado en el rancho San Francisco de la jurisdicción de Sisal. 1 de marzo de 1853. Sisal. Fondo Justicia, 1821-1913. Serie Penal. Sección Juzgado de Primera Instancia de lo Criminal. Subserie Incendio. Caja 67, vol. 67, exp. 2. Agey, Mérida, México.

${ }^{69}$ Causa instruida contra Camila Sandoval por el delito de incendio perpetrado en el rancho San Francisco de la jurisdicción de Sisal. 1 de marzo de 1853. Sisal. Fondo Justicia, 1821-1913. 
un menor de nombre Nicolás Rodríguez, de once años, ${ }^{70}$ y que también formaba parte de la familia de las personas mencionadas ya que se le apunta en el padrón de San Fernando.

Otro hecho que marca la relación entre esos poblados es que, en 1848, Luisa Dambrón, de 26 años, quien aparece en el padrón de 1841 de San Fernando Aké, fungiese como madrina en la boda de Camila Sandoval, realizado en Sisal el 2 de octubre de $1848 .{ }^{71}$ ¿Cómo fueron a parar esas mujeres y el menor, de su natal poblado hasta el lejano rancho de San Francisco de Paula?, ¿de quiénes se hicieron acompañar? El progenitor de Camila se llamaba José María Sandoval, y aparece en el padrón de San Fernando Aké para 1841, reportado como de 40 años, en conjunto con menores del mismo apellido -Fernando, de ocho años, Nicolás de tres años, y Anastacia de un año-, y el nombre de Camila, ${ }^{72}$ más no Isabel Rodríguez, indicada como viuda para $1849 .{ }^{73}$ Las mujeres que aparecen junto a la familia Sandoval, en el padrón de San Fernando, son Manuela Rodríguez, de 29 años, y las hermanas Manuela (26 años) e Isabel Molas, de 28 años.

Por otra parte, en relación con el nombre del poblado, Victoria (2011, pp. 317-319) propuso hace unos años que podría deberse al gobernador de Yucatán Francisco de Paula y Toro (1835-1837), nacido en Cartagena de Indias, hoy Colombia. Ahora quizá la mejor respuesta se tenga en la mención de que en el incendio de la iglesia del rancho, José María Naranjo logró salvar la imagen de San Francisco de Paula que se encontraba en su interior, así como

Serie Penal. Sección Juzgado de Primera Instancia de lo Criminal. Subserie Incendio. Caja 67, vol. 67, exp. 2. AgEy, Mérida, México; Padrón general de los habitantes de Kikil y su comprensión, del partido de Tizimín, con expresión de sexos, edades y ocupación. San Fernando, mayo 12 de 1841. Fondo Poder Ejecutivo. Ramo Padrones. Vol. 3, exp. 27. Agey, Mérida, México.

${ }^{70}$ Padrón general de los habitantes del puerto de Santa María de Sisal y su comprensión, rancho de San Francisco de Paula y Celestún, 1849. Fondo Poder Ejecutivo, 1843-1885. Sección Censos y Padrones. Caja 64, vol. 14, exp. 49. AGEy, Mérida.

${ }^{71}$ Hunucmá. Matrimonios. 1842-1883. Vol. 36, f. 10. AgAY, Conkal, México.

${ }^{72}$ Padrón general de los habitantes de Kikil y su comprensión, del partido de Tizimín, con expresión de sexos, edades y ocupación. San Fernando, mayo 12 de 1841. Fondo Poder Ejecutivo. Ramo Padrones. Vol. 3, exp. 27. AgEy, Mérida, México. Se le menciona en el enlace de Camila. Hunucmá. Matrimonios, 1842-1883. Vol. 36, fs. 9v-10. AGAY, Conkal, México.

${ }^{73}$ Padrón general de los habitantes del puerto de Santa María de Sisal y su comprensión, rancho de San Francisco de Paula y Celestún. 1849. Fondo Poder Ejecutivo, 1843-1885. Sección Censos y Padrones. Caja 64, vol. 14, exp. 49. Agey, Mérida, México. 
algunos muebles del mismo espacio. ${ }^{74}$ Con esa representación religiosa y de la devoción hacia ella, es factible que la titularidad del rancho se debiese al nombre del santo patrón.

En la información del juicio se menciona un comprador de higuerilla (Recinus communis L.), vecino de la villa de Hunucmá, el citado Naranjo, quien fue la única persona señalada en este expediente como "moreno". La presencia de este afrodescendiente en el plano comercial en el rancho indica el cultivo o recolección y venta de higuerilla entre los pobladores, pues el individuo le preguntó sobre ese arbusto o su semilla a Camila y luego fue a casa de Jorge Rivas a comprar cierta cantidad de aquella planta. ${ }^{75}$ Asimismo, ilustra la presencia de otras personas de ascendencia africana en la región, más allá de los moradores del rancho.

Cuando tocó turno a Florencio Rivas ${ }^{76}{ }^{2}$ este declaró que el 19 de febrero estaba llegando del monte con su mula cargada de guano, y al estar bajando los bultos junto al árbol del ceibo "que hay sembrado en medio de la plaza", comenzó a escuchar los gritos de que se quemaba el gallinero de la casa de Pedro Rivas. Aparte de ese dato, en este caso es de notar que tal vez este sujeto se dedicaba al comercio de ese vegetal, y que el ceibo (Ceiba pentandra) pudiese ser un indicador cultural de una asimilación de los pobladores afrodescendientes hacia lo maya del entorno, dada la importancia de ese árbol para los indígenas. En relación con ello, destaca el hecho de que se diga que el ceibo "está sembrado", como si su presencia fuese aposta y no fortuita. ${ }^{77}$

${ }^{74}$ Causa instruida contra Camila Sandoval por el delito de incendio perpetrado en el rancho San Francisco de la jurisdicción de Sisal. 1 de marzo de 1853. Sisal. Fondo Justicia, 1821-1913. Serie Penal. Sección Juzgado de Primera Instancia de lo Criminal. Subserie Incendio. Caja 67, vol. 67, exp. 2. Agey, Mérida, México. Los nombres de Francisco de Paula y Francisca de Paula eran comunes entre los afrodescendiente del siglo xviII en Yucatán (Restall, 2009, p. 395, nota 62), al igual que en los libros consultados del archivo de Matanzas. La imagen salvada del incendio presumiblemente era de bulto.

${ }^{75}$ Causa instruida contra Camila Sandoval por el delito de incendio perpetrado en el rancho San Francisco de la jurisdicción de Sisal. 1 de marzo de 1853. Sisal. Fondo Justicia, 1821-1913. Serie Penal. Sección Juzgado de Primera Instancia de lo Criminal. Subserie Incendio. Caja 67, vol. 67, exp. 2. AgEy, Mérida, México.

${ }^{76}$ Esta persona, hijo de Guillermo y Luisa Rivas, no parece en el padrón de San Francisco de 1849, al igual que su madre, pero al año siguiente contrae nupcias con Calletana [sic] Carrión, hija de Estanislao Carrión y de Eugenia Sandoval, vecinos de Sisal. Hunucmá, 1836-1884. Vol. 37, f. s. d. AGAY, Conkal, México. Esta persona de apellidos Sandoval no parece tener relación con la familia de Camila.

${ }^{77}$ Causa instruida contra Camila Sandoval por el delito de incendio perpetrado en el rancho San Francisco de la jurisdicción de Sisal. 1 de marzo de 1853. Sisal. Fondo Justicia, 1821-1913. 
Por otra parte, descontando a Úrsula Rivas que vendía verduras en Sisal y tal vez a otras mujeres que también lo hiciesen, al parecer todos los hombres del pueblo salían al monte a trabajar quedando en el rancho la mayor parte de personas del sexo femenino. Eso se deduce de las palabras de Pedro Rivas en su intención de interrogar a "todas las mujeres del rancho" acerca del segundo incendio el día 29 de febrero. Si el trabajo de ellos requería retirarse a cierta distancia del sitio por alguna razón, en el caso de ellas tal vez el cultivo de hortalizas, por ejemplo, permitía su permanencia. Camila Sandoval indicó en una de sus participaciones ante el juez que "A las siete de la mañana del expresado día veinte y ocho salí de mi casa con dirección a mi solar que está media cuadra de mi estancia" ${ }^{78}$

Después de interrogatorios y careos, el 10 de marzo de 1853, el juez primero de amparo, licenciado Mariano Brito, dictó auto contra Camila y mandó que guardase prisión en la casa de las recogidas en vez del calabozo de la fortificación de Sisal. No obstante, a comienzos de abril el defensor de la acusada, el licenciado José D. Castro, señaló al Juez de $1^{\mathrm{a}}$ Instancia “que siendo leves los indicios que existen contra mi patrocinada, su culpabilidad cualquiera que resulte queda castigada suficientemente con la prisión sufrida". Alegó que, "la ingenua e inocente confesión que hace de su sueño revela ninguna malicia, no siendo extraña la existencia de tal sueño si se considera que pocos días antes hubo otro incendio en el expresado rancho". ${ }^{79}$ Aquello dio resultado, pues si el 30 de ese mes se confirmó la sentencia contra Camila, el día 12 de abril se indicó que era suficiente el castigo por la prisión que había sufrido hasta el momento, ya que no se consideró daño mayor y se mandó su libertad. ${ }^{80}$

Serie Penal. Sección Juzgado de Primera Instancia de lo Criminal. Subserie Incendio. Caja 67, vol. 67, exp. 2. AGEY, Mérida, México.

${ }^{78}$ Causa instruida contra Camila Sandoval por el delito de incendio perpetrado en el rancho San Francisco de la jurisdicción de Sisal. 1 de marzo de 1853. Sisal. Fondo Justicia, 1821-1913. Serie Penal. Sección Juzgado de Primera Instancia de lo Criminal. Subserie Incendio. Caja 67, vol. 67, exp. 2. Agey, Mérida, México.

${ }^{79}$ Causa instruida contra Camila Sandoval por el delito de incendio perpetrado en el rancho San Francisco de la jurisdicción de Sisal. 1 de marzo de 1853. Sisal. Fondo Justicia, 1821-1913. Serie Penal. Sección Juzgado de Primera Instancia de lo Criminal. Subserie Incendio, Caja 67, vol. 67, exp. 2. Agey, Mérida, México.

${ }^{80}$ Causa contra Camila Sandoval por incendio acontecido en el rancho San Francisco. 18 de abril de 1853. Mérida. Fondo Justicia, 1821-1913. Serie Penal. Sección Tribunal Superior de Justicia. Subserie Incendios. Caja 68, vol. 68, exp. 26; Causa instruida contra Camila Sandoval por el delito de incendio perpetrado en el rancho San Francisco de la jurisdicción de Sisal. 1 de 
No obstante que el alcalde del rancho era pariente político de Camila, este permitió la denuncia contra su nuera en su afán de hacer cumplir la ley y lo estipulado en sus obligaciones. Ello denota que no había alguna otra forma de autoridad interna como fue el caso de San Fernando Aké, que sirviese como contrapeso. Tampoco hay indicios que hubiese una posible identificación grupal africana entre los moradores de esa ascendencia que permitieran arreglar sus asuntos de manera interna.

Sobre este tema, los vecinos de San Francisco de Paula, a pesar de las señaladas menciones de las autoridades como foráneos o "morenos", pudieron sentirse y externarse como yucatecos desde su aceptación al territorio nacional, aunque con San Fernando Aké mantuvieron un lazo con visos de una identificación de procedencia africana. Comulgamos con la idea de que la pérdida $u$ olvido de las raíces africanas tuvo causas multifactoriales (Delgadillo, 2019) en las que se incluyen la decisión de aquella gente por identificarse como mexicanos después de la independencia en una búsqueda de ascenso social (Guardino, 2008) y también por el silenciamiento de la prensa debido a prejuicios raciales. En el caso yucateco, la prensa regional no hizo señalamiento a la presencia de gente de ascendencia africana en las décadas posteriores a la independencia (1821). Así, una búsqueda en la prensa yucateca de 1830 a 1860 en la Hemeroteca Nacional Digital de México, únicamente ofreció una mención de "morenos" para ese lapso y hace referencia a los de San Fernando ${ }^{81}$ En consecuencia, es lícito pensar que en la región peninsular no se tenían las mismas condiciones de debate y uso político de la afrodescendencia que en el centro del país, donde los periódicos, a opinión de Delgadillo (2019), denotan que el tema siguió formando parte de la vida pública con esos fines en los años 1840-1860.

Parte interesante de la información recabada en este trabajo es saber que Camila Sandoval o Rodríguez, junto con algunos familiares y una persona de servicio, y la Dambrón, todas registradas en San Fernando Aké para 1841, se trasladó a San Francisco de Paula, desde el oriente al poniente penin-

marzo de 1853. Sisal. Fondo Justicia, 1821-1913. Serie Penal. Sección Juzgado de Primera Instancia de lo Criminal. Subserie Incendio. Caja 67, vol. 67, exp. 2. AGEy, Mérida, México.

${ }^{81}$ Se buscó la palabra "moreno" por ser la que se encuentra en referencia a los afrodescendientes para aquellos años. Existen entradas con las palabras "esclavo" o "negro", pero hacen referencia a asuntos literarios o foráneos al país. Por su parte, Taracena (2007, p. 36), en su estudio sobre el periódico El Museo Yucateco, publicado de 1841 a 1842, señala que en sus textos no existen referencias a los "mulatos y mestizos", más allá de los de índole literaria. 
sular para vivir en pareja. Ese matrimonio obliga a preguntar dónde y cómo se conocieron Camila y Camilo ya que esa relación es testimonio de contactos entre dos poblados fundados por afrodescendientes en Yucatán.

No se tiene documento alguno que señale el periplo de las personas antes citadas desde San Fernando Aké hasta San Francisco de Paula, lo más seguro es que fuese por vía marítima, aunque en esa ocasión ya no podía ser Miguel Molas quien los condujese pues había fallecido en 1840, aproximadamente, y ellas aparecen en el padrón de San Fernando Aké al año siguiente.

\section{CONSIDERACIONES}

Es gratificante que, de pocos datos hasta hace unos años, ahora se cuente con nueva información que ayude a interpretar el arribo de gente de la Cuba colonial al Yucatán independiente, y que con el tiempo formaron el rancho San Francisco de Paula. Por ahora se sostiene la postura de que siete de los fundadores de ese sitio fue gente que llegó a Yucatán desde la región de Matanzas vía Nueva Málaga, hasta el pueblo de San Fernando Aké, para luego marchar a la zona de Sisal. Con el tiempo quizá llegaron desde esa isla algunos más. En ese proceso construyeron su historia para hacerse de una identidad, trabajando como moradores del rancho y en compañía de otras personas de ascendencia no africana, en diversas labores del campo y del comercio.

Ante su arribo, la autoridad yucateca vio en ellos la posibilidad de sentirse progresista y les otorgó beneficios de acorde a la coyuntura política del momento en la región; fueron sin duda, adaptaciones "en pro de la humanidad". Este hecho pudo tener una significancia especial en el contexto político yucateco del momento, a pesar de no saber a ciencia cierta su situación legal en el lugar de salida, dado que en la documentación generada únicamente se les señala como "negros bozales".

Un interesante descubrimiento en esta historia es la relación que se dio entre los dos poblados fundados por africanos y afrodescendientes en Yucatán, lo que indica una identificación entre ellos, más allá de su procedencia caribeña inmediata. El traslado de un grupo de personas (los nuevos Rivas), acaso por rencillas internas como se apuntó, se complementa con la posterior marcha de Camila Sandoval y parentela de San Fernando Aké hacia San Francisco de Paula, aunque tampoco se descarta el contacto en ambos sentidos. 
De igual manera, resulta relevante el papel que Miguel Molas desempeñaría en la historia de ese tráfico humano ya que, de acorde a la propuesta, el experto navegante del litoral yucateco y contrabandista tuvo una participación importante en la misma.

San Francisco de Paula fue un sitio donde los inmigrantes tuvieron que rehacer sus vidas e identidades, adaptándose culturalmente. Con el paso del tiempo, los fundadores aceptaron la inclusión de otras personas de distinta procedencia, por lo que el asentamiento se fue diversificando en lo poblacional, formas de pensar y de actuar. Estos datos documentados acerca de la presencia de gente no afrodescendiente y de indígenas en el rancho dibuja un asentamiento que, si bien fue mayoritariamente de personas de origen africano, no tuvo reparos en abrirse a otras en la búsqueda de dejar atrás su otredad y seguir por la vía de la homogeneidad nacional, y sentirse yucatecos y mexicanos, a pesar de algunos señalamientos por parte de la autoridad con resabios colonialistas de un pasado no lejano. Ante esas condiciones, la historia del poblado debió seguir en el mismo sendero que las restantes comunidades yucatecas, sin ninguna notoriedad, a lo que ayudó sobremanera la prensa de esos años que se habría de encargar de no hacer notorios en el plano público el pasado y el presente de los africanos y afrodescendientes.

Para escoger Yucatán como destino y salir de la Cuba hispana y convulsa, los inmigrantes debieron conocer de antemano las condiciones políticas existentes en el estado. En el territorio mexicano podrían vivir en el marco de libertad, con posibilidad de un ascenso social, otorgando mayor énfasis a la nueva situación que tenían y que, con el correr de los años, pasó a enmarcarse en el mestizaje afro-maya de la vida rural yucateca.

Por último, llama la atención que la historia oral no mencione la procedencia matancera de algunos de ellos, ni de los lazos con San Fernando Aké, pero que sí tergiverse el actuar de Eugenio Duarte al ser señalado como persona de importancia en el escape hacia la esclavitud. Quizá la presencia de Bernavel Duarte en Sisal responda a ello contando una versión a conveniencia.

Esta historia mínima sacada de los añejos escritos, contribuye a enriquecer lo que hasta ahora se sabe de un tercer grupo social que vivía en los albores del Yucatán independiente, y en particular del pequeño asentamiento. Es una historia que entrelaza a la Cuba colonial con el Yucatán independiente, en esa histórica relación circuncaribeña (ínsula-península) que ilustra la presencia de los afrodescendientes en el siglo XIX, hasta ahora poco conocida en la región peninsular. 
Mapa 1. Mapa de parte del Caribe, indicando el derrotero entre los sitios de Matanzas, Cuba, Nueva Málaga, San Fernando Aké y San Francisco de Paula

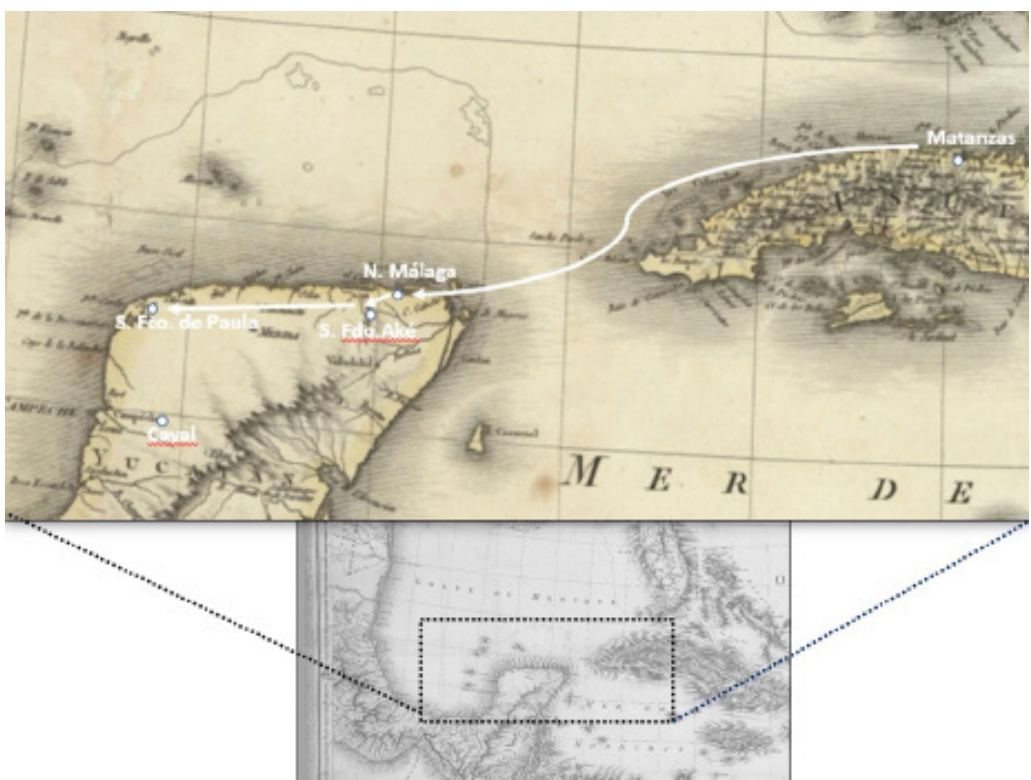

Fuente: detalle del mapa Unites States. West Indies, realizado por P. Tardieu, P. Lapie y C. Piquet, 1806. Recuperado de https://www.reddit.com/r/ MapPorn/comments/2qt3oj/an_1806_map_of_the_united_states_and_west_indies/ Editado por Alejandro Molina E. 


\section{LISTA DE REFERENCIAS}

Antochiw, M. (1992). Historia cartográfica de la península de Yucatán. México: Tribasa/ Gobierno del Estado de Campeche.

Arrow, S. (1988). Las mujeres de la ciudad de México, 1790-1857. México: Siglo XXI Editores.

Balboa, I. (2002). Brazos para el azúcar. Centralización y productividad laboral. En J. A. Piqueras (comp.), Azúcar y esclavitud en el final del trabajo forzado (pp. 50-75). Madrid: Fondo de Cultura Económica.

Bretones, F. (2013). Noticias Insurgentes. Política, escravidâo e imprensa periódica em Cuba no contexto das independências ibero-americanas (1810-1823). (Tesis de maestria inédita). Universidade de São Paulo, São Paulo.

Delgadillo, J. E. (2019). La esclavitud, la abolición y los afrodescendientes: memoria histórica y construcción de identidades en la prensa mexicana, 1840-1860. Historia Mexicana, LXIX(2), 743-788.

Farriss, N. (1992). La sociedad maya bajo el dominio colonial. La empresa colectiva de la supervivencia. Madrid: Alianza Editorial.

Fernández, F. y Negroe, G. (1995). Una población perdida en la memoria. Los negros de Yucatán. Mérida: Universidad Autónoma de Yucatán.

Ferrer, M. (2002). La crisis independentista en Yucatán. Anuario de Estudios Americanos, 59(1), 121-146.

García, G. (2005). Vertebrando la resistencia: la lucha de los negros contra el sistema esclavista. En M. D. González-Ripoll, C. Naranjo, A. Ferrer, G. García y J. Opatrný, El rumor de Haití en Cuba: temor, raza y rebeldía, 1789-1844 (pp. 233-320). Madrid: Centro Superior de Investigaciones Científica.

Guardino, P. (2008). La identidad nacional y los afromexicanos en el siglo xIx. En B. Connaughton (coord.), Prácticas populares, cultura política y poder en México, siglo XIX (pp. 259-301). México: Universidad Autónoma Metropolitana/Casa Juan Pablos.

Herrera, L. (1991). Piezas de Indias. La esclavitud negra en México. Veracruz: Instituto Veracruzano de la Cultura.

Landers, J. (2011). Comunicación y movilidad de afrodescendientes en el Circuncaribe. En J. de la Serna (ed.), Vicisitudes negro-africanas en Iberoamérica, experiencia de investigación (pp. 241-263). México: Universidad Nacional Autónoma de México.

Meriño, M. de los Á. y Perera, A. (2015). Contrabando de bozales en Cuba: perseguir el tráfico y mantener la esclavitud (1845-1866). La Habana: Ediciones Montecallado. 
Naranjo, C. (2017). Cuba, reformismo, poder y conflictos (1760-1868). En J. Alvarado Planas (coord.), La administración de Cuba en los siglos XVIII y XIX (pp. 47-68). Madrid: Boletín Oficial del Estado/Centro de Estudios Políticos y Constitucionales.

Olavarría, E. y Arias, J. (1972). México a través de los siglos (x vols.). México: Editorial Cumbre.

Olveda Legaspi, J. (2013). La abolición de la esclavitud en México, 1810-1917. Signos Históricos, 15(29), 8-34.

Peón, J. y Gondra, I. (1832). Colección de leyes, decretos y órdenes del Augusto Congreso del Estado Libre de Yucatán (II vols.). Mérida: Imprenta de Lorenzo Seguí.

Restall, M. (2009). The Black Middle: Africans, Mayas, and Spaniards in Colonial Yucatan. Stanford: Stanford University Press.

Robles, F. y Andrews, A. (2004). Proyecto Costa Maya. Reconocimiento arqueológico de la esquina noroeste de la Península de Yucatán. En J. P. Laporte, B. Arroyo, H. Escobedo y H. Mejía (eds.), XVII Simposio de Investigaciones Arqueológicas en Guatemala, 2003 (pp. 41-60). Guatemala: Museo Nacional de Arqueología y Etnología. Recuperado de https://www.asociaciontikal.com/ simposio-17-ano-2003/06-03-robles-y-andrews-doc/

Rodríguez, S. (1985). Geografía política de Yucatán (3 vols.). Mérida: Universidad Autónoma de Yucatán.

Ruiz, R. (2001). Matanzas. Surgimiento y esplendor de la plantación esclavista (1793-1867). Matanzas: Ediciones Matanzas.

Ruz, R. (1970). La emancipación de los esclavos en Yucatán. Mérida: Ediciones de la Universidad de Yucatán.

Shrimpton, M. (2015). Islas de tierra firme ¿un modelo para el Caribe continental? El caso de Yucatán. Memorias, 11(25), 178-208.

Stephens, J. (1984 [1843]). Viajes a Yucatán. Mérida: Editorial Dante.

Taracena, A. (2007). El Museo Yucateco y la reinvención de Yucatán. La prensa y la construcción del regionalismo yucateco. Península, II(1), 13-46.

Victoria, J. (2015). Corrupción y contrabando en la península de Yucatán. De la colonia a la independencia. Mérida: Conaculta/Sedeculta.

Victoria, J. (2011). San Fernando Aké y San Francisco de Paula. Dos poblados de negros (libres) en Yucatán, siglos XVIII y XIX. En J. de la Serna (ed.), Vicisitudes negro africanas en Iberoamérica, experiencia de investigación (pp. 287-331.). México: Universidad Nacional Autónoma de México.

Victoria, J. y Canto, J. (2006). San Fernando Aké. Microhistoria de una comunidad afroamericana en Yucatán. Mérida: Universidad Autónoma de Yucatán. 
Von Grafenstein, J. (1997). Nueva España en el Circuncaribe, 1779-1808. Revolución, competencia imperial y vínculos intercoloniales. México: Universidad Nacional Autónoma de México.

\section{OTRAS FUENTES}

Archivos

AGAY Archivo General del Arzobispado de Yucatán.

AGEY Archivo General del Estado de Yucatán.

AGI Archivo General de Indias.

ANC Archivo Nacional de Cuba.

ESSSS Ecclesiastical and Secular Sources for Slave Societies. 